\title{
AN ANALYSIS OF DAVID AND EMILY CALLAWAY'S PSYCHOPATH PROBLEMS IN HIDE AND SEEK MOVIE VIEWED FROM SIGMUND FREUD'S PSYCHOANALYSIS THEORY
}

\author{
Dean Rahmat Fuady \\ Sekolah Tinggi Bahasa Asing- IEC Jakarta \\ deanrahmatfuady@gmail.com \\ Suhendar \\ Sekolah Tinggi Bahasa Asing- IEC Jakarta \\ suhendar@stibaiec-jakarta.ac.id
}

\begin{abstract}
APA Citation: Fuadi, D.R., Suhendar (2019). An Analysis of David And Emily Callaway's Psychopath
Problems in Hide and Seek Movie Viewed from Sigmand Freud's Psychoanalysis Theory. Journal of

English Language and literature, 4(2), 57-67. DOI 10.37110/jell.v4i02.81
\end{abstract}

Received: 05-07-2019

Accepted: 15-08-2019

Published: 01-09-2019

\begin{abstract}
This research aims to analyze the main characters in Hide and Seek movie as the characters who have psychopathic problem and Dissociative Identity Disorder. In relation to which, the writer studied Hide and Seek movie as the unit of analysis. Psychopathic problems viewed from Sigmund Freud's psychoanalysis concepts are used for the review of related literature theories or concepts of the research. Therefore, the method of the research is descriptive qualitative, which tries to explain about the intrinsic elements of the movie; such as characterization and the scenes of the movie, then followed by analyzing them through Sigmund Freud's psychoanalysis. Through observations of the scenes and the behavior of the main characters the writer reveals David and Emily have been identified to have psychopathic characters such as manipulative, parasitical, deceitful, power hungry, less empathy, often lie, shallow affect and poor behavioral control. In addition, the causes of such character are trauma and stress viewed from Sigmund Freud's psychoanalysis theory.
\end{abstract}

Keywords: Psychopath, DID, Psychopathic, Psychoanalysis, Characters

\section{INTRODUCTION}

Literatures which has an origin from Latin word "Littera" are written works, especially those considered superior or lasting artistic merit. In general, literary work is a work that is formed from an author's imagination. It is also an expression of the images and events of daily activity conducted directly or indirectly. Literary works have function to entertain or teach something to the readers. The function of this literature can be found in any kinds of literary works. The works of literature have many forms; they are poetry, novel, comic, soap opera, electronic literature, graphic novel, film or movie and etc.

Literature is the class of writings in which imaginative expression, aesthetic form, universality of ideas, and permanence are characteristic features, as fiction, poetry, romance and drama. Literary quotations and time-worn stereotypes exert a deplorable influence on our thinking. They lead us to consider certain open questions as settled, certain puzzling problems as solved.

Furthermore, movie is one kind of literary works also known as film is a type of visual communication which uses moving pictures and sound to tell stories or inform.

Film offers a special language of projected moving images which is sounded by a language which incorporates the characteristics of the graphic, plastic, spatial, and narrative arts. Film is finally accepted in educational circles as an established art form suitable for study analysis, research in institution of higher learning. Film study encompasses the examination of the motion picture as a medium of communication, 
entertainment and artistic expression. (Film study is not to be confused with the teaching of other subject matters by using film or television as audio-visual instructional technology).

In this modern era, film has been growing to be an interesting industry for the people who want to express their creative thoughts and skills. Most of cinemas consider that film as a media to share their ideas and opinions about some phenomena in the real life; and to see it as a promising business as well since most people like to spend their spare times by watching film.

Finally, In this research the writer decided to use "Hide and Seek" movie directed by John Polson as the object of the analysis. The movie was released on January 28, 2005 in US. This is an American psychological horror-thriller film starred by Robert De Niro \& Dakota Fanning as the main characters. The writer would like to analyze the main character named David \& Emily Callaway in this movie with Sigmund Freud's psychoanalysis theory.

\section{LITERATURE REVIEW}

\section{Definition of Psychopath}

Psychopath is a person suffering from chronic mental disorder with abnormal or violent social behaviour and can appear normal, even charming. Sometimes considered synonymous with sociopath, is traditionally defined as a personality disorder characterized by persistent antisocial behavior, impaired empathy and remorse. Psychopath is a symptom that indicates that someone is having an imbalance or a failure in harmonizing constructive and destructive impulses in itself, which is usually triggered by the pressures of life or experiencing an emotional trauma that causes the conflict making him/her manipulative, volatile and often criminal actions.

The word Psychopathy and its application means the contact of the spirit of man with his body, with reference to the laws relating to their healthful adjustment and harmonization. Whatever pertains to man's physical and spiritual natures, while the two are in contact, is related to this system; indeed, whatever affects man physically, mentally or spiritually, during his life here on earth, pertains to Psychopathy.
There are many traits and characteristics of psychopaths, Listed below is the Hare Psychopathy Checklist-Revised, a diagnostic tool used to identify psychopathic traits. It was compiled by Dr. Robert Hare, Emeritus Professor of Psychology at the University of British Columbia, where he has taught and conducted research for more than four decades, devoting most of his academic career to the study of psychopathy.

\section{Interpersonal Traits of a Psychopath}

1. Pathological lying - Can be moderate or high; in moderate form, they will be shrewd, crafty, cunning, sly, and clever; in extreme form, they will be deceptive, deceitful, underhanded, unscrupulous, manipulative, and dishonest.

2. Glib and superficial charm - The tendency to be smooth, engaging, charming, slick, and verbally facile. Psychopathic charm is not in the least shy, self-conscious, or afraid to say anything. A psychopath never gets tonguetied. They have freed themselves from the social conventions about taking turns in talking, for example.

3. Grandiose self-worth - A grossly inflated view of one's abilities and self-worth, selfassured, opinionated, cocky, a braggart. Psychopaths are arrogant people who believe they are superior human beings.

4. Conning and manipulativeness - The use of deceit and deception to cheat, con, or defraud others for personal gain; distinguished from pathological lying in the degree to which exploitation and callous ruthlessness is present, as reflected in a lack of concern for the feelings and suffering of one's victims.

The most well-known interpersonal trait of a psychopath is their pathological lying. Psychopaths lie constantly to cover up their psychopathic traits and antisocial (often illegal) behaviors.

\section{Affective of Emotional Characteristics of a Psychopath}

1. Lack of remorse or guilt - A lack of feelings or concern for the losses, pain, and 
suffering of victims; a tendency to be unconcerned, dispassionate, cold-hearted, and non-empathic. This item is usually demonstrated by a disdain for one's victims.

2. Shallow affect - Emotional poverty or a limited range or depth of feelings; interpersonal coldness in spite of signs of open gregariousness.

3. Callousness and lack of empathy - A lack of feelings toward people in general; cold, contemptuous, inconsiderate, and tactless.

\section{Failure to accept responsibility for own} action - A failure to accept responsibility for one's actions reflected in low conscientiousness, an absence of dutifulness, antagonistic manipulation, denial of responsibility, and an effort to manipulate others through this denial.

Based on the writer's point of view it concludes that the emotions of a psychopath also have specific traits. One such emotional characteristic is the lack of remorse or guilt. This psychopath emotional characteristic explains why psychopathic killers can commit heinous acts such as murder and not feel bad about them.

\section{Lifestyle Psychopathic Traits}

1. Parasitic lifestyle - An intentional, manipulative, selfish, and exploitative financial dependence on others as reflected in a lack of motivation, low self-discipline, and inability to begin or complete responsibilities.

2. Lack of realistic, long-term goals - An inability or persistent failure to develop and execute long-term plans and goals; a nomadic existence, aimless, lacking direction in life.

3. Impulsivity - The occurrence of behaviors that are unpremeditated and lack reflection or planning; inability to resist temptation, frustrations, and urges; a lack of deliberation without considering the consequences; foolhardy, rash, unpredictable, erratic, and reckless.

4. Irresponsibility - Repeated failure to fulfill or honor obligations and commitments; such as not paying bills, defaulting on loans, performing sloppy work, being absent or late to work, failing to honor contractual agreements.

5. Need for stimulation or proneness to boredom - An excessive need for novel, thrilling, and exciting stimulation; taking chances and doing things that are risky. Psychopaths often have low self-discipline in carrying tasks through to completion because they get bored easily. They fail to work at the same job for any length of time, for example, or to finish tasks that they consider dull or routine.

6. Promiscuous sexual behavior - A variety of brief, superficial relations, numerous affairs, and an indiscriminative selection of sexual partners; the maintenance of several relationships at the same time; a history of attempts to sexually coerce others into sexual activity or taking great pride at discussing sexual exploits or conquests.

7. Many short-term marital relationships A lack of commitment to a long-term relationship reflected in inconsistent, undependable, and unreliable commitments in life, including marital.

Accordingly, the writer concludes that not only psychopathic traits can be seen in the emotions and interpersonal aspects but they can also be seen in the lifestyles of psychopaths as well. One such lifestyle trait is a parasitic lifestyle where the psychopath uses and feeds off of others. He or she likely does this by utilizing the interpersonal traits noted above.

\section{Antisocial Traits of Psychopaths}

1. Juvenile delinquency - Behavior problems between the ages of 13-18; mostly behaviors that are crimes or clearly involve aspects of antagonism, exploitation, aggression, manipulation, or a callous, ruthless toughmindedness.

2. Early behavior problems - A variety of behaviors prior to age 13, including lying, theft, cheating, vandalism, bullying, sexual 
activity, fire-setting, glue-sniffing, alcohol use, and running away from home.

3. Poor behavioral controls - Expressions of irritability, annoyance, impatience, threats, aggression, and verbal abuse; inadequate control of anger and temper; acting hastily.

4. Revocation of condition release - A revocation of probation or other conditional releases due to technical violations, such as carelessness, low deliberation, or failing to appear.

5. Criminal versatility - A diversity of types of criminal offenses, regardless if the person has been arrested or convicted for them; taking great pride at getting away with crimes. The word psychopath can be replaced with the word sociopath throughout this page. The meaning is very similar, if not the same.

From the matters stated hereinabove, the writer concludes that antisocial traits of psychopaths are the traits that go against the society's conventions. For example, juvenile delinquency and early behavioral problems which constitutes antisocial traits that many psychopaths have. These severe problems leave parents wondering, "Is my child a psychopath?"

\section{Dissociative Identity Disorder}

Taken from www.psychologytoday.com dan the reference from Cardwell C. Nuckols, $\mathrm{PhD}$ writer The Diagnostic and Statistical Manual of Mental Disorders, here are the definitions :

Dissociative identity disorder (DID) is a severe condition in which two or more distinct identities, or personality states, are present inand alternately take control of-an individual. Some people describe this as an experience of possession. The person also experiences memory loss that is too extensive to be explained by ordinary forgetfulness. DID formerly referred to as multiple personality disorder, is a condition wherein a person's identity is fragmented into two or more distinct personality states. People with this rare condition are often victims of severe abuse.

DID is still sometimes called multiple personality disorder (MPD). This is because many people experience the changes in parts of their identity as completely separate personalities in one body. In fact the parts of someone identity are all part of one personality but they are not joined up or working together as a whole.

DID is characterized by presence of two or more distinct personality states or an experience of possession and recurrent episodes of amnesia. Persons with DID experience recurrent intrusions into conscious functioning and sense of self voices; dissociated actions and speech; intrusive thoughts, emotions and impulses. DID experiences alterations of sense of self attitudes, preferences and feeling like one's body or actions are not their own odd changes of perception (depersonalization or derealization-detached from one's body while cutting) and intermittent functional neurological symptoms (seizure like symptoms, hippocampal shrinking, etc.)

\section{Symptoms}

The following criteria must be met for an individual to be diagnosed with dissociative identity disorder :

1. The individual experiences two or more distinct identities or personality states (each with its own enduring pattern of perceiving, relating to, and thinking about the environment and self). Some cultures describe this as an experience of possession.

2. The disruption in identity involves a change in sense of self, sense of agency, and changes in behavior, consciousness, memory, perception, cognition, and motor function.

3. Frequent gaps are found in memories of personal history, including people, places, and events, for both the distant and recent past. These recurrent gaps are not consistent with ordinary forgetting.

4. These symptoms cause clinically significant distress or impairment in social, occupational, or other important areas of functioning.

\section{Causes}

The disorder may first manifest at any age. Individuals with DID may have post-traumatic symptoms (nightmares, flashbacks, and startle 
responses) or post-traumatic stress disorder. Several studies suggest that DID is more common among close biological relatives of persons who also have the disorder than in the general population. As this once rarely reported disorder has grown more common, the diagnosis has become controversial. Some believe that because DID patients are highly suggestible, their symptoms are at least partly iatrogenic-that is, prompted by their therapists' probing. Brain imaging studies, however, have corroborated identity transitions.

\section{Treatments}

The primary treatment for DID is long-term psychotherapy with the goal of deconstructing the different personalities and uniting them into one. Other treatments include cognitive and creative therapies. Although there are no medications that specifically treat this disorder, antidepressants, anti-anxiety drugs or tranquilizers may be prescribed to help control the mental health symptoms associated with it. With proper treatment, many people who are impaired by DID experience improvement in their ability to function in their occupational and personal lives.

From the description stated hereinabove, the writer concludes that DID is characterized by two or more personalities within the individual who have post-traumatic symptoms (nightmares, flashbacks, and startle responses) or post-traumatic stress disorder. The good news is, even though DID is a severe mental illness, the treatment of DID is available and curable.

\section{Psychoanalysis}

Psychoanalysis is the most recent and advanced therapeutic procedure for the treatment of the neuroses. It is what its name implies, an analysis of the mind. Other psychotherapeutic methods deal only with the superficial manifestations of the neuroses and therefore cannot produce a fundamental cure. Psychoanalysis concern itself primarily with the cause of symptoms, with their real underlying mechanism. It not only penetrates into the origin of symptoms, but the analysis at the same time is the treatment.

Psychoanalysis is certainly a psychological and psychotherapeutic theory and all other connected concepts. An Austrian Physicist, Sigmund Freud created this theory and it is further stemmed up by Josef Breuer and others. So, Sigmund Freud is called father of Psychoanalysis. In his theory he explained many concepts dealing with human psychology.

Breuer and Freud also found that "it is therapeutic to recall and relieve emotional trauma that has been made unconscious (in a process called repression) and release some of the emotional material became known as catharsis". The understanding of the inner material causing the obvert symptoms was referred to as insight. Breuer's systematic treatment of hysterical symptoms of Anna O. provided scientific considerations about the effect of catharsis in treating neurotic illness.

Psychoanalysis is considered to be a HighLevel theory containing various sub theories such as "levels of consciousness", "psychic structure of personality", "psychosexual development", "defence mechanisms" and "theory of instincts", and it serves to unify them to some extent.

The first requirement of the analyst is a sympathetic attitude towards his material. The pooh-pooh a symptom as "nonsense," as "imagination," as "silly," as "make believe," or "malingering," is an assumption which has no value from the standpoint of the understanding of the symptom. Such an approach to mental problems is rather an index of the naïveté and indolence of the assumer. These universal human attributes must be reckoned with and overcome. Thus the analyst becomes a good listener. This listening does not mean the turning of an indulgent ear to the plaints of the sufferer, but a comprehending and grasping curiosity that counts "nothing as trivial, nothing as fortuitous." The analyst must hunger for information about the patient's ills, being ever on guard against formulating interpretations before the returns are all in.

Psychoanalysis, therefore, is still far from exercising an exhaustive or even an extensive influence in the domain of sociology. Nevertheless, it is undeniable that even to-day psychoanalysis, leaving its own immediate field to enter the field of social science, can 
render here services of considerable importance.

In the individual who has a healthy soul, these three systems (id, ego, and superego) is the composition of a unified and harmonious. By working together on a regular basis, the three systems that allow an individual to move efficiently and satisfactorily in its environment.

Essentially, the concepts in Freud's psychoanalysis theory briefly summarized by Umesh D. Wagh which will be useful while actually analysing the films are :

\section{Unconscious}

Unconscious is a part of mind where human keep their repressed desires, fears, memories, mories, fantasies, without knowing it consciously. Almost $70 \%$ of our mind consists of these unconscious things.

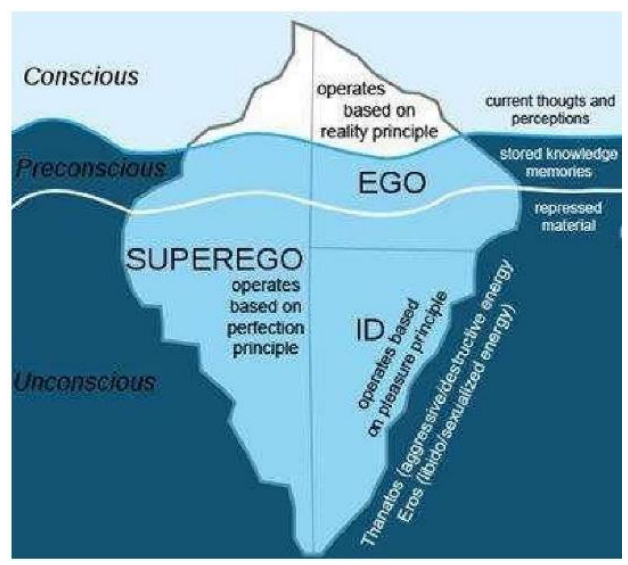

Figure 1. Iceberg Model.

As shown in Figure 1 which is iceberg model of personality structure, it can be seen that most of the part which is below the water is unconscious. And also that it's hidden below the conscious.

\section{Id, ego and superego}

Iceberg model also shows three very important concepts of human psychology : id, ego and superego. Id operates based on pleasure principle and it generally deals with basic drives. Superego operates based on perfection principle which kind of deals with human thoughts about human social status. And ego is actually balancing the former two. It operates based on reality principle. For example,

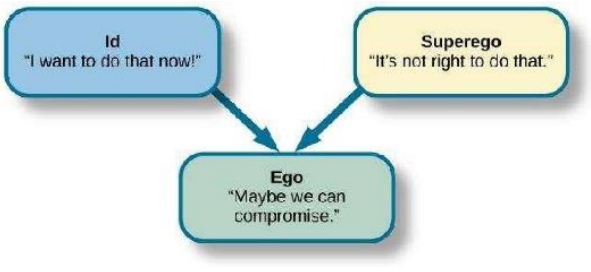

Figure 2. Id, Ego and Superego.

\section{Sexuality}

Sexuality deals with the sexual or physical desires human have, they may be conscious or unconscious in nature. Each person has his/her own space which is generally hidden in his/her unconscious. The sexual instinct is represented by a force called "libido".

Sexual, urinary and fecal activities being controlled by the same nerves develop along parallel lines. All of them, however, are submitted to a severe regulation which in the case of sex amounts to almost complete repression.

\section{Oedipus complex and Electra complex}

During some years of childhood, especially at phallic phase and genitals phase of development, it happens that the child feels this unconscious attraction towards his/her opposite gender parent. That is, for boys, they are attracted to their mother, which is called as Oedipus complex and in case of girls, they are attracted to their father, which is called as Electra complex.

\section{Defence mechanism}

These are nothing but the techniques implemented by the ego in order to control instincts and ward off anxieties. There are different ways of defence mechanisms including ambivalence, repression, avoidance, suppression, denial, rationalization, fixation, regression, identification, projection etc.

\section{Dreams}

Dreams are generally the result of the combination of our conscious as well as unconscious thoughts. They actually show and make us almost feel the wish fulfilment or fears or fantasies.

\section{Aggression and guilt}

Aggression is an instinctual action controlled by mainly id and it disrupts 
superego. And then the powerful force that is brought into action by ego is guilt.

All of these concepts are part of our real life and films are nothing but the implementation of different incidents or imaginations which either can happen in real life or can be imagined in real life. Though, for some films, the world shown in the film and the story of the film is not at all part of the real world, but after all it's an imagination, a creation by a human being and he/she is real. So even if it's a fantasy film or fiction film, as it is created by someone's imagination, it is connecting to the audience, as all psychological concepts like above are part of it.

From the abovementioned theory, the writer concludes that firstly, psychopaths literally means mentally ill. The sufferer is also often referred to as a sociopath because of antisocial behavior and harms the closest people. People with psychopathic label are often referred to as "crazy people without mental disorders". Secondly, Dissociative Identity Disorder is part of Psychopath problem which can create multiple personalities and makes people unaware of what he/she does. Lastly, Sigmund Freud the father of Psychoanalysis says that human psyche has a central role in human life. He also describes that human personality is like an iceberg - the peak of which can be seen above the ocean represented as human conscious mind which is too small if compared to such a part that is invisible under the ocean represented as human unconscious mind.

\section{METHOD}

Looking at the questions and the purposes of the research, then the writer decides to use qualitative method in conducting this research. "Qualitative researches study things in their natural settings, attempting to make sense of, or to interpret, phenomenon in terms of the meaning people bring to them.

\section{FINDING AND DISCUSSION}

\section{Psychopath Problems}

\section{David Callaway}

When exposed to the psychopathic side of David and formally introduced to Charlie, Charlie exhibits psychopathic tendencies such as: manipulative, parasitical, deceitful, power hungry and especially lacking empathy. Everytime Emily said Charlie made her do it, shows that he was manipulating her. After David realizes he is Charlie, Charlie takes control because he is afraid to lose the power he has. Charlie goes on a rampage, killing the sheriff, attacking Katherine and even going after his own daughter. Although DID may create one identity that is more aggressive, it is not a regular occurrence of that identity becoming psychopathic, hence why it is a separate disorder.

\section{Emily Callaway}

Emily is a 9 year old girl who gets trauma because of her mother's suicide. She seems happy and well adjusted in the scenes before she sees her mother's bodied corpse in the bathtub. Affective or emotional characteristics of a psychopath like lack of remorse or guilt, Shallow affect, callousness and lack of empathy showed when she uses insects as a bait when fishing and behave cold or hostile towards her father throughout the film. Even at the beginning of the film before she is traumatized, she seems closer to her mother.

\section{Discussion}

\section{Characteristics}

\section{David Callaway}

A psychologist man, Dr. David Callaway suffered from Dissociative Identity Disorder. Charlie is an alternate personality of David's. David realizes that he has a split personality and that Charlie is not imaginary at all: Charlie in reality is David. Whenever it appeared David was in his study, Charlie was actually in control. David also realizes that under his Charlie personality, he murdered his wife and made it appear to be a suicide. He also fully recalls the events of the party the night before his wife's murder, where he had caught his wife cheating on him, which triggered David's identity disorder. As Charlie, David goes on a murder spree. He viciously bludgeons the local 
sheriff with a shovel and drags his body to the cellar.

The two main mental disorders in this movie are psychopathy and Dissociative Identity Disorder. DID is when someone has 2 or more distinct identities that alternately control a person's behaviour. The fact that throughout the movie David becomes Charlie and Charlie controls his actions (i.e. killing his wife and Elizabeth) is proof that he suffers from DID. He also does not initially remember these actions which is another symptom of the disease. For the most part, the disease is portrayed quite accurately by the movie as David appears to be quite passive and doesn't remember the actions caused by Charlie while Charlie is aggressive and hostile and retains the majority of memories. This fits with the typical symptoms associated with DID.

The main cause for DID is trauma, extreme stress and/or anxiety. David remembers once entering his study that he and his wife were at a party and he walked in on her cheating him, and that is when Charlie was created. Charlie then killed his wife and made it appear as a suicide. Because DID can create selective amnesia, David truly believed that his wife had killed herself. One night, David founds out who is really behind all the deaths. He looks through boxes of miscellaneous things and it triggers his memories, and these memories make him become conscious of his second identity.

Some dissociative experiences include identity shifting and changing, speaking in a different voice or voices, using a different name or names, switching between different parts of your personality, feeling as if you are losing control to „someone else', experiencing different parts of your identity at different times, acting like different people, including children. A doctor or psychiatrist might call these experiences identity alteration.

\section{Emily Callaway}

Shortly after moving into their new house, Emily begins to talk about her new friend Charlie. Audience thinks that she met him on move in day when she wandered off into the woods and found a cave. In fact, Emily herself says that she first met Charlie on that day. She may have become indirectly aware of Charlie's presence before that time, as Emily was already sullen, withdrawn and wary around strangers on the day they arrived at their new home in Woodland. Her sullenness and withdrawal can also be explained as a normal reaction to the trauma of her mother's death.

There are three suggestions why Emily would purposely disfigure the face of Amy's doll, Penelope. First, the writer feel that she did it out of dislike for Amy's aunt Elizabeth, because Elizabeth was getting too close to David and trying to take her mother's place. Second, she did it in order to frighten Amy into staying away so that Charlie wouldn't hurt her. The third possibility is that Emily was displaying the pathological side of herself.

Why did Emily wear her dead mother's clothes for her dinner with David and Elizabeth? This is where antisocial traits of psychopaths is shown in Emily, presumably for the same reasons that she disfigured the face of Amy's doll. She wanted to scare Elizabeth away. She says that Charlie told her that her dad liked Elizabeth as much as he liked Alison, and she feared that Elizabeth was getting too close to David. Consequently, she tried to scare Elizabeth away by acting macabre. When Elizabeth simply told her that she looked dressed up and beautiful, Emily went to plan B and began talking about how her mother committed suicide and how she hopes that the same thing doesn't happen to Elizabeth.

At first, Emily seems to like Charlie. She is protective of him and doesn't want David or anyone else to know about him. She likes playing hide-and-seek with him and tells Katherine that she and Charlie even have a private game, the goal being to upset her father. As Charlie's misdeeds begin to pile up, however, Emily becomes more and more afraid of him, such that she calls Katherine on the phone and tells her that she doesn't want to be with Charlie anymore and that she's afraid her father cannot protect her from him. Pathological lying showed when she doesn't tell to her father about Charlie because "Charlie" makes it clear that he does not like David. And when she doesn't tell the truth about Elizabeth whereabout to the sheriff. Most likely, she was worried about her father's safety and what would happen to him if she told the truth. 
At the end of the movie, Emily drew a picture in her new home. She draws herself with two heads, implying that she may also have DID, which would be understandable considering she found out her father killed her mother and then tried to kill her. Her father was then killed. That is a lot of trauma for such a young child and it would make sense for her to create something to help her cope.

\section{Psychopath Problems}

Freud saw the psyche structured into three parts, the id, ego and superego, all are developing at different stages in human lives. These are systems, not parts of the brain, or in any way physical aspect. According to Freud's model of the psyche, the id is the primitive and instinctual part of the mind that contains sexual and aggressive drives and hidden memories, the super-ego operates as a moral conscience; and the ego is the realistic part that mediates between the desires of the id and the super-ego. Although each part of the personality comprises unique features, they interact to form a whole, and each part makes a relative contribution to an individual's behaviour.

According to the explanation above, the writer concludes that id, ego, and superego in David and Emily showed in some scenes:

\section{Id}

Id is the source of all psychic energy so that Id is the main component in someone's personality. Id is the only personality component present at birth, the personality aspect is conscious and includes both instinctive and primitive behavior. Id is driven by the principle of pleasure that seeks to meet all human wants and needs, if it doesn't meet then there will arise anxiety and tension. For example, when someone is feeling hungry or thirsty, they will soon meet those needs by eating or drinking until the id is fulfilled.

Id is operated at an unconscious level according to the pleasure principle and comprises two kinds of biological instincts, life and death instinct. First, "life instinct, helps the individual to survive; it directs life-sustaining activities such as respiration, eating, and sex". The energy created by the life instincts is known as libido. Second, "death instinct is viewed as a set of destructive forces present in all human beings". When this energy is directed outward onto others, it is expressed as aggression and violence. Life is stronger than death instinct, thus enabling people to survive rather than self-destruct.

From the explanation above, the writer concludes that Id in David showed life instinct it was seen when David ran out with a kitchen knife then met with his neighbor who he thought as the bad guy. He unconsciously, accidentally cut his neighbor's hand and injures him by a kitchen knife to save himself. Then death instinct showed when Charlie is on as an alter persona committing violence and being aggressive. It all works in the subconscious of human minds. This alter personality has been manipulating poor traumatized Emily and has been committing horrible crimes. After this epiphany, Charlie takes control of David's body and goes on a murderous rampage.

Whilst, throughout the movie the writer sees Emily moves to follow the needs of her life like playing, making her imaginary friends, drawing picture under unconsciousness probably because trauma that befell her. Once in their new home, Emily goes into a wooded area behind the house, she drops her beloved doll, signifying that she lost her core, innocent persona. Emily however did not simply drop the doll that represents her innocence. She literally mutilates it. All that is done unconsciously.

\section{Ego}

The ego is a personality component that is responsible for dealing with reality. The ego develops from the id and ensures that the impetus of the id can be expressed in an acceptable way in the real world. The function of the ego is in the conscious, and unconscious mind. In other words the ego function is to filter out the impulses that the Id wants to satisfy in reality.

The ego is "that part of the id which has been modified by the direct influence of the external world". The ego develops in order to mediate between the unrealistic id and the external real world. It is the decision making component of personality. Ideally the ego works by reason, whereas the id is chaotic and totally unreasonable. 
This Ego as David's tool to refuse and triggering the existence of Charlie, when he is still in the conscious realm the alter persona can not replace his core personality and vice versa. During the first part of the movie, whenever the Charlie alter is triggered, audiences can see David is sitting in his study, wearing headphones and listening to music. This symbolizes his core/real persona being "put on hold" while Charlie is in control of his body. David is "out of service" and oblivious to what is going on. Therefore David never actually sat in his study: It shows that his core persona was on hold while Charlie was triggered.

Then for Emily who had previously sided with Charlie, as things progress in the movie Emily realizes that the fun Charlie is actually evil and sadistic. While the writer doesn't ever see Charlie actually programming Emily during the movie, audiences can clearly see the symptoms and the switch in Emily's behaviour.

\section{Superego}

The superego is an image of an awareness of the values and morals of society grown by customs, religion, parents, and the environment. Basically the superego is a conscience, so the superego provides guidelines for making judgments, whether it is true or false. Superego present in the conscious, preconscious and unconscious mind. Id, Ego and Superego influence each other.

The superego's function is to control the id's impulses, especially those which society forbids, such as sex and aggression. It also has the function of persuading the ego to turn to moralistic goals rather than simply realistic ones and to strive for perfection.

The superego consists of two systems: The conscience and the ideal self. The conscience can punish the ego through causing feelings of guilt. For example, if the ego gives in to the id's demands, the superego may make the person feel bad through guilt. The ideal self is an imaginary picture of how you ought to be, and represents career aspirations, how to treat other people, and how to behave as a member of society.

The writer concludes that superego in David Callaway is when he attempts to help his daughter to snap out of her trauma by leaving his job as a psychologist and by moving to a small town outside of New York. There, he realizes that his relationship with Emily is extremely difficult and that her behaviour is increasingly worrisome. David believes that Charlie is an imaginary friend of Emily created to help cope with her trauma. When David discovers his potential new girlfriend who has been murdered in the bathtub, he begins to think that Charlie is a real person and that he's extremely dangerous.

While superego in Emily is shown in the first scene and some in the last scenes of the movie. First, Emily is a regular and playful child who appears to be very happy, she likes to play hide-and-seek with her mother, who then lovingly tucks her into bed. Then in the last scenes, when she tries to escape from Charlie's pursuit and she decides to go hide in the cave, she is sure that her real father is already replaced by Charlie as a core personality.

\section{CONCLUSION}

David and Emily's characteristics problem as the main characters in Hide and Seek movie are the consequence from the trauma. Both David and Emily have their own traumatic events. David suffered from Dissociative Identity Disorder because he was cheated by his wife, it causes an alter ego or other personality having emerged and he killed his wife, but he's not realized it yet, he still thinks his wife committed suicide. While psychopath problems in Emily appear after she witnessed the apparent suicide of her mother, after that she displays symptoms of severe trauma. So that she suffered from one incident inflict another.

In analyzing movie, the writer should use the appropriate theory or approach in order to have maximal comprehension of the movie itself. In this thesis, the writer uses Sigmund Freud's psychoanalysis theory, psychopath and dissociative identity disorder to deepen the id, ego, superego and character analysis development of main characters in Hide and Seek movie. However, it is possible for the other researchers who want to analyze this movie by using another approach or theory in analyzing it, and they can focus on the same issues or aspects in the movie that the writer doesn't analyze yet to get broader comprehension of the movie. 


\section{REFERENCES}

Barlow, David H. \& Durand, Mark V. 1995. Abnormal Psychology : An Integrated Approach, New York: Brooks/Cole Publishing Company.

Coriat, Isador H. 1919. What is Psychoanalysis?, New York: Moffat, Yard and Company

Deighton, Lee C. 1971. The Encyclopedia of Education, USA: The Macmillan Company and the Free Press.

Denzin NK. \& Lincoln YS. 1994. Handbook of Qualitative Research, Thousand Oaks: Sage Publications.

Dissociative Identity Disorder (Multiple Personality Disorder), Retrieved September 29, 2017, from https://www.psychologytoday.com/conditio ns/dissociative-identity-disorder-multiplepersonality-disorder

Farrel, B.A. 1981. The Standing of Psychoanalysis, Oxford: Oxford UP.

Foster, Clare. 2016. Understanding dissociative disorders, London: Mind

Freud, Sigmund. 1920. Beyond the pleasure principle, $\mathrm{SE}$.

Freud, Sigmund. 1923. The ego and the id, SE.

Freud, Sigmund. 1925. Negation. Standard edition, 19.

Hall, Calvin S. 1954. Sigmund Freud: Introduction to Psychoanalysis, Ohio,
Cleveland: The World Publishing Company.

Hare, Robert. 2017. Psychopathic Traits, Retrieved September 29, 2017, from https://www.sociopathicstyle.com/psychop athic-traits/

Jelliffe, Smith E. 1918. The Technique of Psychoanalysis, New York and Washington: Nervous and Mental Disease Publishing Company.

Kolnai, Aurel. 1921. Psychoanalysis and Sociology, London: George Allen \& Unwin Ltd.

Nuckols, Cardwell C. 2013. The Diagnostic and Statistical Manual of Mental Disorders, Fifth Edition, USA: American Psychiatric Association.

Rush, Benjamin 1890. Psychopathy or Spirit Healing, Rogers Park Ill: William Richmond.

Tridon, André 1920. Psychoanalysis and Behavior, New York: Alfred A. Knopf, Inc.

Tridon, André 1921. Psychoanalysis Sleep and Dreams, New York: Alfred A. Knopf, Inc.

Wagh, Umesh D. 2013. Psychoanalysis film theory - Animated Films, Bombay: IDC, IIT

Webster 1974. The New Golier Webster International Dictionary of The English Language, Massachusetts: The English Language Institute Of America Inc. 